\title{
Elastic property of damaged zone inferred from in-situ stresses and its role on the shear strength of faults
}

\author{
Kiyohiko Yamamoto, Namiko Sato, and Yasuo Yabe \\ Graduate School of Science, Tohoku University, Sendai 980-8578, Japan
}

(Received January 4, 2002; Revised August 14, 2002; Accepted August 29, 2002)

\begin{abstract}
The Nojima fault in Hyogo prefecture, Japan, ruptured during the 1995 Hyogo-ken Nanbu earthquake $\left(M_{\mathrm{JMA}}=\right.$ 7.3). The stress measurements at sites close to this fault have revealed that the direction of the largest horizontal stress is almost perpendicular to the strike of this sub-vertical fault and that, in the zone within about $100 \mathrm{~m}$ from the fault core axis, the ratio of the largest shear stress to the normal stress is significantly small compared with that of the outside. It is thus the logical consequence that the principal stress outside the zone tends to direct perpendicularly to the fault plane. A model called the fracture process model is introduced for the relationship between fracture strength and elastic property of rocks. Making use of this model on the assumption that the observed shear stress equilibrates to the shear strength of damaged zone, it is found that the elastic wave velocities estimated from the stress well explain the observed velocities of damaged zone. This model suggests further that the friction coefficient of fault can be smaller than 0.15 due to the characteristic deformation of damaged zone and that the pressurized fluid is not essential for the formation of weak faults.
\end{abstract}

\section{Introduction}

The strength of faults is essential for modeling the deformation process of the earth's crust. The constitutive law for frictional sliding is substantial for modeling the earthquake generation process. For these studies, it is most basic to clarify the shear strength of faults that have been naturally formed. The frictional coefficient of faults inferred from laboratory experiments is equal to or more than about 0.6 (e.g. Byerlee, 1978). On the other hand, the frictional strength for the San Andreas Fault inferred from the heat flow data is very small (Brune et al., 1969). The recent data of well borehole breakouts and of hydraulic fracturing measurement appear to support that the San Andreas Fault is weak. The friction coefficient of the fault is estimated to be about 0.1 or so in appearance (Zoback et al., 1987). The San Andreas Fault and some faults in the San Andreas Fault system have been shown to be weak from the seismological and geological data and some faults even for intra-plate earthquakes as well (Jones, 1988; Oppenheimer et al., 1988; Chester et al., 1993; Iio, 1997).

Some ideas have been proposed to compensate the gap in the frictional strength between the San Andreas Fault and the simulated faults in laboratories. It is well known that pressurized pore fluid reduces the compressive or shear strength of rocks (e.g. Handin et al., 1963). One of the ideas is that the pressurized pore fluid is sealed in fault zone (e.g. Sibson et al., 1988). Deep drilling was conducted at Cajon Pass at about $3 \mathrm{~km}$ from the San Andreas Fault to measure the stress and the pore fluid pressure directly at depths (e.g. Coyle and Zoback, 1988; Zoback and Healy, 1992). However, they

Copy right(c) The Society of Geomagnetism and Earth, Planetary and Space Sciences (SGEPSS); The Seismological Society of Japan; The Volcanological Society of Japan; The Geodetic Society of Japan; The Japanese Society for Planetary Sciences. have found neither the evidence that the shear strength of the fault is normal in magnitude nor the evidence that the fault zone is saturated with pressurized fluid. Further, the deep drillings of $12.2 \mathrm{~km}$ at greatest that have been conducted worldwide so far have suggested that the upper crust is hydraulically permeable in general (Barton et al., 1995; Huenges et al., 1997; Zoback and Townend, 2001).

The frictional strength of simulated faults is expressed to be the product of the friction coefficient and the normal stress to the fault plane. According to Byerlee (1978), the friction coefficient is about 0.85 for small normal stress on fault planes and about 0.60 for larger normal stress. The compressive strength of intact rock specimens is approximately represented by the Coulomb's criterion. The criterion is represented to be the sum of cohesion force and the frictional strength. The frictional strength is expressed to be the product of the internal friction coefficient and the normal stress. The internal friction coefficient ranges from 0.5 to 1.5 (e.g. Paterson, 1978). This coefficient is almost comparable in magnitude to the coefficient of friction. This permits us to suspect that the both friction coefficients are the appearances of the same mechanical property of materials. This property has to be taken into consideration as one of the constraints for the discussion of the frictional strength.

The fracture strength is defined from the macroscopic viewpoint, or in terms of average stresses, as a rule. In order to compare the friction coefficient of a fault with that from laboratory experiments, the friction coefficient of the fault should be determined from the average stress over the fault plane at the time when the rupture starts to propagate at a point. It is clear thus that the stresses only at a few sites are insufficient to determine the friction coefficient, even if they are close to the fault. 
The stress is one of the independent state variables. The stress measurement is thus the only way to clarify the strength of faults in principle. The measurement can be generally performed only at shallow depths compared with the seismogenic depths and the spatial distribution of the sites for measurement may usually be sparse compared with the spatial variation of stress. For these reasons, alternative methods are necessarily required to get the information about the stress state at depths.

This paper presents a simple model of faults in order to discuss the frictional strength of faults from the macroscopic viewpoint. The model shows that the elastic property of damaged zone plays an important role on the strength. Yamamoto $(1995,1998)$ has proposed a model called the fracture process model that yields the shear strength of rocks microscopically fractured. Making use of the model together with the theories of effective elastic constants of composites, the elastic wave velocities of damaged zone are estimated from the in-situ stresses measured at sites close to the Nojima fault. The velocities are compared with those of the damaged zone for some faults to examine the applicability of the model of faults. Further, the strength of fault is discussed on the elastic properties of damaged zone thus estimated.

\section{Brief Review of the Stress Field near the Nojima Fault}

Stresses have been measured in holes drilled at three sites close to the Nojima fault immediately after the 1995 Hyogoken Nanbu earthquake $\left(M_{\mathrm{JMA}}=7.3\right)$. Ikeda et al. $(2001)$ and Tsukahara et al. (2001) employed the hydraulic fracturing technique (HF) for the in-situ measurement and Sato et al. (1999) and Yamamoto and Yabe (2001) applied the deformation rate analysis (DRA) to rock core sample recovered from the holes. DRA has been developed to measure the stresses based on the rock property of stress memory (Yamamoto et $a l ., 1990)$. The stresses measured by DRA are expected to be the stress before the earthquake, while the stresses by HF are those after the earthquake. Some details of the DRA measurement on the Nojima cores are described in our previous paper (Yamamoto and Yabe, 2001).

The measurement sites are shown in Fig. 1. The HF and the DRA measurements were performed for the same holes at sites, TSM and IKH and for the different holes close to each other at HRB. The holes are distinguished by the subscripts GSJ and NIED, respectively. The results of DRA are reviewed in this section, being compared with the results by HF. The arrows show the directions $\theta_{\mathrm{hmax}}$ of the largest horizontal stress determined by DRA.

\subsection{Definition of $\boldsymbol{r}$-value}

In order to discuss the stresses in relation to the shear strength of the earth's crust, a parameter $r$ defined by

$$
r=\left(\sigma_{L}-\sigma_{S}\right) /\left(\sigma_{L}+\sigma_{S}\right)
$$

is introduced, where $\sigma_{L}$ and $\sigma_{S}$ are the largest and the smallest principal stress of compression. The shear strength of rocks increases proportionally to the normal component of the stress on the fault surface in general. Therefore, the parameter $r$ may be thought as an index of the potential of the stress field for shear fracture. The value of $r$ is calculated here on the assumption that one of the principal directions is in the vertical. If a fault parallel to the maximum shear plane begins to rupture at $r=r_{s}, r_{s}$ corresponds to the apparent friction coefficient of the fault. The parameter $r$ is referred to as $r$-value or potential stress hereafter.

\subsection{Stress orientation}

Figure 1 shows the directions $\theta_{\mathrm{hmax}}$ of the largest horizontal stress determined by DRA (Sato et al., 1999). IKH is located near the southern end of the buried fault extended from the surface break. Sato (1999) has pointed out that the rotation of $\theta_{\text {hmax }}$ at IKH occurs in the zone of small $r$-value of about 0.2 . According to Ito et al. (1997), there is a fracture zone around the depth of $670 \mathrm{~m}$. Except for shallow depths of IKH, $\theta_{\text {hmax }}$ approximately lie in the NW-SE direction. They are almost perpendicular to the fault strike. The apparent friction coefficient at TSM, which is calculated from the stresses measured by DRA at depths about 310 and 415 , never exceeds the magnitude of 0.3 (Yamamoto and Yabe, 2001).

The directions determined by HF and the observation of bore hole breakouts lie in the NW-SE direction, too (Ito et al., 1997; Tsukahara et al., 2001; Ikeda et al., 2001). Referring to the horizontal strain from 1885 to 1985 observed by Geographical Survey Institute, Japan (Geographical Survey Institute, 1997), the direction $\theta_{\mathrm{hmax}}$ is nearly equal to that of the largest contraction of the Osaka bay area adjacent to the sites. This implies that the NW-SE direction of $\theta_{\mathrm{hmax}}$ has not been formed after the faulting, but suggests that the stress reflects the tectonic situation of the fault even in the vicinity of the fault in this case.

\subsection{Shear stress magnitude}

The $r$-values at TSM are determined to be about 0.5 . This means that in the vicinity of the fault there are areas where $r$-value is close to the fracture strength of the intact rocks that are free from major flaws, while the apparent friction coefficient of the fault is not larger than 0.3 (Yamamoto and Yabe, 2001). This is caused by the fault that is not optimally oriented. Tsukahara et al. (2001) performed the $\mathrm{HF}$ measurement at two depths near $1,500 \mathrm{~m}$ in the same hole. The stresses at these depths are of almost pure strikeslip regime and the $r$-values for these depths are about 0.16 . The small $r$-value and the strike slip regime mean that the stress field at the depths reduces toward the lithostatic state and that the apparent friction coefficient never exceeds 0.16 . Although these $r$-values at the large depths are very small compared with those at small depths by DRA, the apparent friction coefficients appear to be common to both the small and the large depths.

Ikeda et al. (2001) carried out the measurement by HF in Hole $\mathrm{HRB}_{\mathrm{NIED}}$ drilled by NIED. This hole locates close to Hole $\mathrm{HRB}_{\mathrm{GSJ}}$. Their measurement has revealed that the site is in the reverse fault regime and the $r$-values are between 0.3 and 0.4 for the depth smaller than about $800 \mathrm{~m}$. On the other hand, the stresses are in the strike slip regime and the $r$ values are nearly equal to or smaller than 0.2 at depths near $1,200 \mathrm{~m}$. The characteristics of the small $r$-value and the strike-slip regime for the depth near 1,200 $\mathrm{m}$ are quite similar to those at the large depths of TSM.

Sato (1999) obtained the stresses around $350 \mathrm{~m}$ in depth for $\mathrm{HRB}_{\mathrm{GSJ}}$ by DRA. The stresses are characterized with the strike slip regime and the relatively small $r$-values. These 


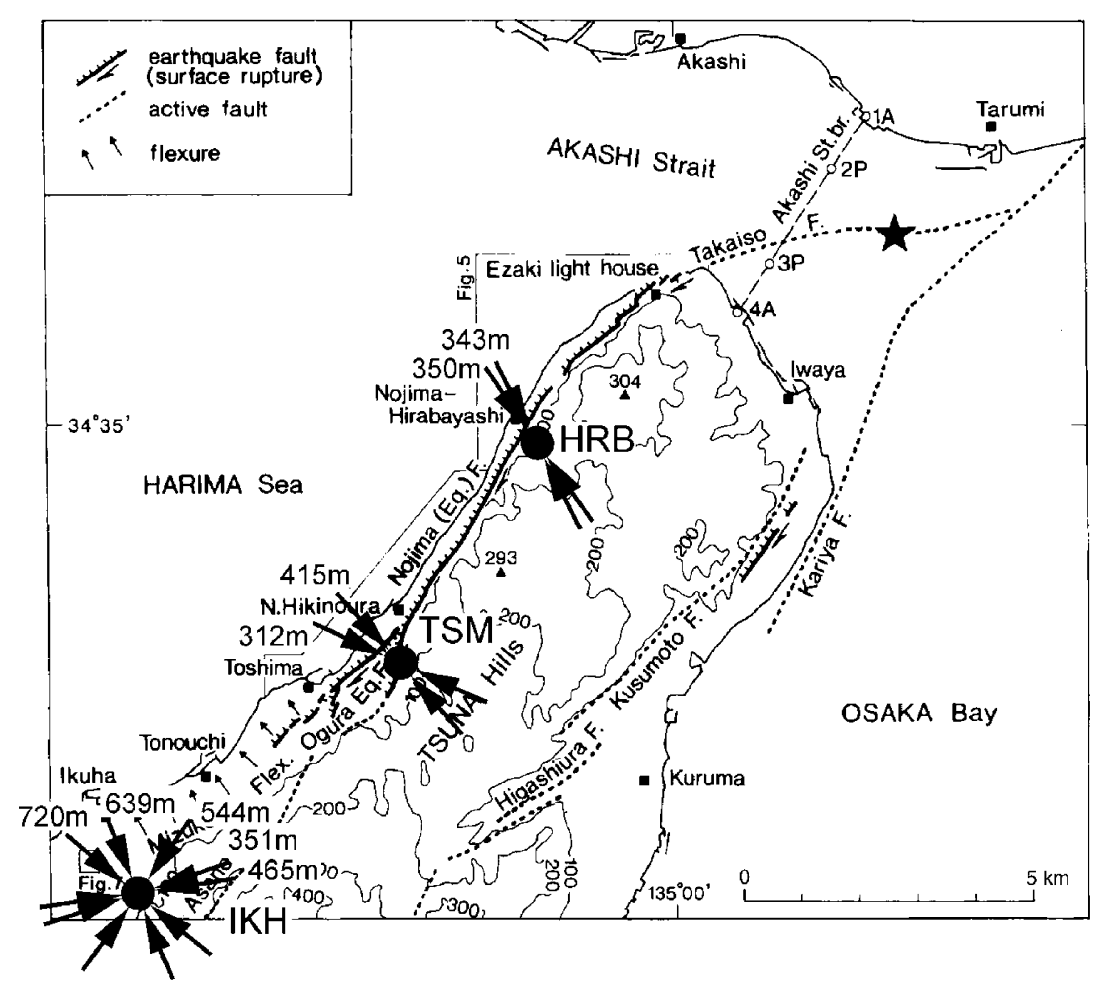

Fig. 1. The site locations for the stress measurement by DRA along the Nojima fault in Awaji Is., Hyogo Pref., Japan. The arrows indicate the directions of the largest horizontal stress of compression determined by DRA at the depths indicated near the respective arrows (data after Sato, 1999). The map is modified from Awata et al. (1996).

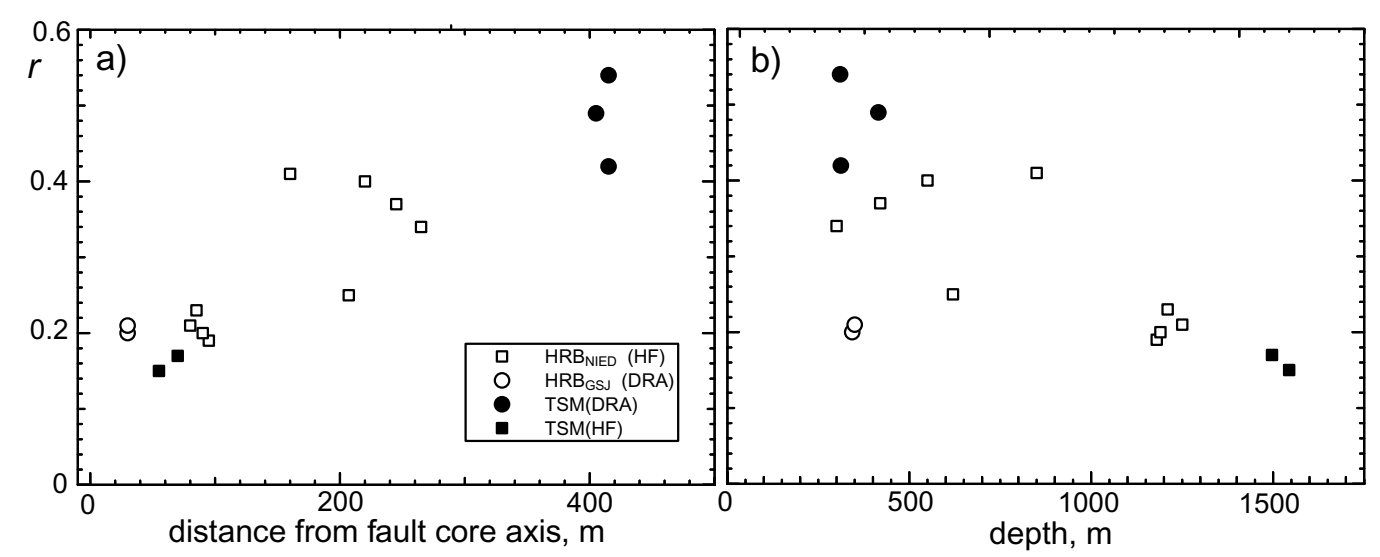

Fig. 2. Relationships of $r$-value to the distance from the fault core axis (a) and to depth (b). The difference in symbol means the difference in the method

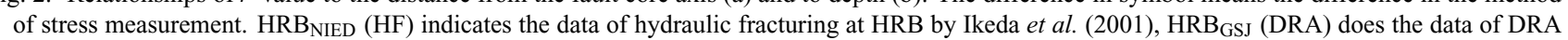
at HRB $_{\text {GSJ }}$ by Sato (1999). TSM (DRA) and TSM (HF) respectively mean the data of DRA at TSM by Sato (1999) and those of hydraulic fracturing by Tsukahara et al. (2001). This figure is modified from Sato (1999).

characteristics are different from those at shallow depths of $\mathrm{HRB}_{\mathrm{NIED}}$, but rather similar to those at greater depths of $\mathrm{HRB}_{\text {NIED }}$ and TSM. The HRB $\mathrm{HSJ}_{\text {GS }}$ locates approximately at a distance of about $50 \mathrm{~m}$, while $\mathrm{HRB}_{\mathrm{NIED}}$ at a distance of about $400 \mathrm{~m}$ from the fault on ground surface. Taking account of these distances relative to the fault, the small $r$ value is considered to reflect the property of the fault zone. Sato (1999) showed the relationship of the $r$-value to the distance of the measuring points from the fault core axis. The relationship is shown in Fig. 2 together with the relationship to depth. The small shear stress near the fault core is clearly seen in this figure. It may be thus reasonable to conclude that the small shear stress is caused not by the change in the stress with depth but depends on the distance of measuring points from the fault core axis. Further, the small $r$-value may be caused not by the stress drop due to the faulting associated with the earthquake, because the small values are determined by the both methods of DRA and HF. The small magnitude of shear stress may be one of the characteristics of the stress state in the zone close to the center of a fault. The width of the zone of small $r$-value is about $100 \mathrm{~m}$ in the case of the Nojima fault. 


\section{Role of Damaged Zone on Shear Strength of} Fault

\subsection{Definition of damaged zone}

Here, the terminology by Chester et al. (1993) or Tanaka et al. (1999) is employed for fault structure as a rule. In the case of the Nojima fault, Ito et al. (1996) and Tanaka et al. respectively have pointed out from the geophysical and the geological data that there are damaged rocks of a few tens meter width a side along the fault core axis. The $r$-value is small in the zone within about $100 \mathrm{~m}$ from the fault core axis, as described above. The small $r$-value is considered thus to be originated from the small shear stress in the zone containing the fault core and damaged rocks around the fault core. We call the zone as the damaged zone. Since the measured stresses by DRA are considered to be those before the earthquake, the small $r$-values obtained by DRA imply that the damaged zone has grown up with repeated faulting.

The stress state in the zone is schematically illustrated in Fig. 3(a). The largest principal stress directs almost perpendicularly to fault plane in order to contract the zone. This simplification of the stress state is considered to be justifiable from the observational results of internal structure of faults by Chester et al. (1993) except for the simple shear zone in the fault core axis. According to them, the strain in the fault zone may be modeled as simple shear in the fault core and nearly fault normal contraction in the bounding damaged zone and host rock.

\subsection{Bounds of shear strength of fault}

Rocks around the fault core have heavily damaged. This implies that the strain is concentrated around the fault core. If the strain is elastic, large strain means large stress. Figure 2 shows that the shear stress is decreased in spite of the large strain concentrated near the fault core. It is reasonable thus to consider that the small shear stress is caused by the small shear strength of damaged rocks. Their small shear strength can also explain the reason why one of the principal stress axes is nearly perpendicular to the fault plane at least in
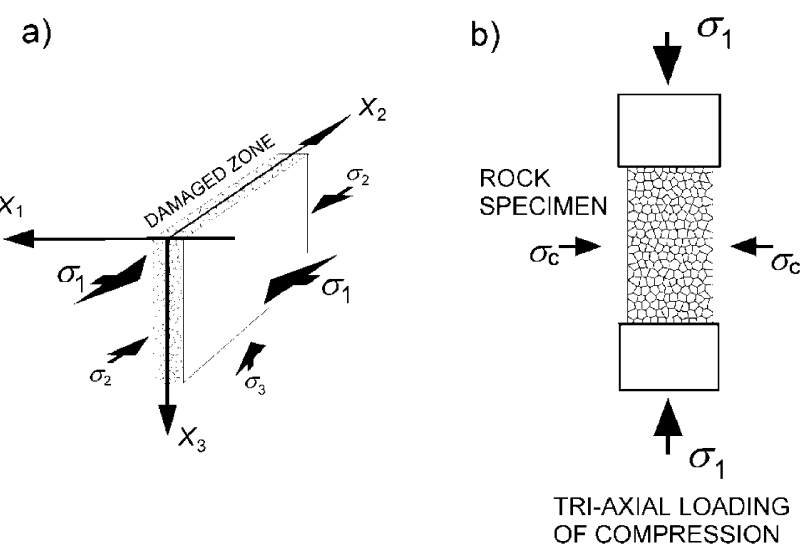

Fig. 3. a) Schematic illustration of the principal directions of compressive stress acting to the damaged zone. The coordinates taken for the damaged zone is shown together. One of the principal directions is taken to be orthogonal to the fault plane. The principal stresses are denoted by $\sigma_{i}$. For the Nojima fault, the $x_{1}$ axis is taken to be orthogonal to the fault plane and the $x_{3}$ axis is taken to be in the depth direction and the stress $\sigma_{1}$ is the largest. b) A rock specimen under the loading test of tri-axial compression and the coordinate defined for the specimen. or near the damaged zone. However, the small strength of damaged zone is not a sufficient condition for weak faults from a macroscopic viewpoint.

We make the three assumptions as follows to discuss the strength of faults as defined in Section 1. 1) Fault is completely locked before faulting from the macroscopic viewpoint. This permits us to take the frictional stress out of consideration and to take the deformation around the fault to be elastic. The frictional strength may be called the shear strength at this time. 2) Fault plane consists of asperity areas and aperture areas as shown in Fig. 4. Asperities mean the parts of a fault that have the same strength as the host rock. Damaged zone means the apertures filled with damage rocks. 3) The fracture of asperities means the fracture of a fault.

There may be many modes of rupture propagation in actual, for example, abrupt slipping, stable sliding, those on a single fault plane, those on multiple fault planes and so on. These modes of rupture propagation may be the ways to release the strain energy stored in rocks surrounding a fault and/or faults. The rupture propagation initiates at or just after the time when the applied stress reaches the fracture strength of rocks. The rupture propagation is here presumed to be independent from the loading process defined for the process just prior to the time when rupture propagation starts. The process is called the fracture process here. The rupture propagation should be thus argued distinctively from the fracture process.

Asperities are assumed to behave as intact rocks. According to the Coulomb's criterion for failure, shear strength increases with an increase in the normal stress on the shear plane where shear fracture occurs. It is assumed for simplicity that the effect of the geometry or the spatial distribution of asperities on the stress concentration can be ignored. In the case that the apertures are void or hydraulically permeable,

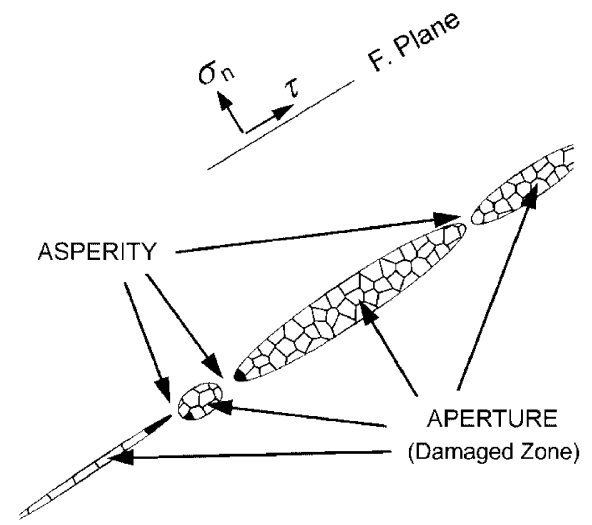

Damaged Zone: Aperture filled with damaged rocks (Damaged rocks: Large Young's modulus and small rigidity)

Fig. 4. Image of the horizontal cross-section of a vertical fault for the discussion of the macroscopic strength. Asperity means the part of a fault zone where the rocks on the both sides of a fault plane completely contact with each other. The fracture zone is defined as the aperture filled with fractured rocks. $\sigma_{n}$ and $\tau$ denote the average normal stress and the average shear stress applied to the fault plane. 
the average normal stress $\sigma_{a s}$ at asperities may be written as

$$
\sigma_{a s}=\sigma_{n} / S
$$

$\sigma_{n}$ being the normal stress averaged over the fault plane and $S(\leqq 1)$ being the fraction of the asperity area to the total area of fault plane. Then, the strength of the fault $\tau_{s}$ may be expressed by

$$
\tau_{s}=S \tau_{0}+\mu S \sigma_{a s},
$$

where $\tau_{0}$ and $\mu$ are the cohesion and the internal friction coefficient of asperities. Therefore, when $S$ is small, the shear strength $\tau_{s}$ of the fault is expressed by

$$
\tau_{s} \approx \mu \sigma_{n}
$$

The strength is seen to be independent of $S$. This may be a rough explanation for the frictional strength that is approximately equal to the internal frictional coefficient of intact rocks and is approximately constant independently of contact area.

Consider the case that the apertures are filled with completely incompressible material with negligibly small rigidity for simplicity, as illustrated in Fig. 4. In this case, the normal stress in the asperities is not expected to change with the change in $S$, while the shear stress $\tau_{a s}$ at asperities builds up with a decrease in $S$. The strength $\tau_{s}$ of fault is thus written as

$$
\tau_{s} \approx S \mu \sigma_{n}
$$

The strength $\tau_{s}$ decreases with a decrease in the fraction $S$ or an increase in the aperture area or the damaged zone. This implies that the shear deformation of fracture zone, which is larger than the contraction, makes the strength of fault decrease. This simple model suggests that the elastic property and structure of fracture zone play an important role on the strength of faults.

\section{Relationship between Stress and Elastic Prop- erty}

\subsection{Fracture process model}

Micro-cracks are increasingly produced in rock specimens under tri-axial loading of compression when applied axial stress is monotonously increased. This means that the applied stress is equal to the fracture strength of the specimen that contains the micro-cracks produced so far. The relationship of crack density to applied stress difference obtained for the specimen may be thus interpreted as the relationship between the strength of the specimen and the density of the cracks included in the specimen.

Figure 3(b) illustrates a specimen, where the Cartesian coordinate is defined in order that $x_{1}$ in the direction parallel to the loading axis. Matsushima (1960) measured the P-wave velocity on rock specimens of a kind of granite under confining pressure $\sigma_{C}$. From his experimental data, Yamamoto $(1995,1998)$ has derived the relationship between applied shear stress and density of tensile cracks, provided that cracks orient their surfaces parallel to $x_{1}$ and distribute their normal lines symmetrically around $x_{1}$. The relationship is given as follows:

$$
c=C f\left(\sigma_{C}\right) G(u) .
$$

Here, the crack density $c$ is defined by

$$
c=\phi / \alpha
$$

$\phi$ and $\alpha$, respectively, are porosity and aspect ratio of cracks. $u$ is the applied shear stress normalized by the shear strength of the specimen. The expression (6) is derived based on the experimental data for the confining pressure ranging from 0.040 to $0.355 \mathrm{GPa}$.

$C f\left(\sigma_{C}\right)$ is a function proportional to $\sigma_{C}^{-p}, p$ is approximately $1 / 2$. When $f\left(\sigma_{C}\right)$ is taken to be unity at $\sigma_{C}=0.1$ $\mathrm{GPa}, C$ is approximately 10 . If the lithostatic pressure approximates the average stress at a depth, $C f\left(\sigma_{C}\right)$ may be written by

$$
C f\left(\sigma_{C}\right) \approx 10 \times\left\{\left(\rho_{\text {rock }} g d-p_{\text {pore }}\right) / 0.1\right\}^{-1 / 2},
$$

where $\rho_{\text {rock }}, g$ and $d$, respectively, are the density of overburden rocks, the gravitational acceleration and the depth. $p_{\text {pore }}$ denotes the pore pressure in the tensile cracks. When the pore pressure is equal to the hydrostatic pressure, $\sigma_{C}$ is given by

$$
C f\left(\sigma_{C}\right) \approx 10 \times\left\{g d\left(\rho_{\text {rock }}-\rho_{\text {pore }}\right) / 0.1\right\}^{-1 / 2},
$$

where $\rho_{\text {pore }}$ is the density of pore fluid. When pore fluid is pressurized or sealed, crack density may be larger than that in the case of the hydrostatic pore pressure.

The function $G(u)$ represents the fracture density. The fracture density is defined to be the volume fraction occupied in a specimen by the volume elements that have lost their strengths by shear micro-fracture. Here, the following are assumed; 1) all the elements have the same size, 2) their shear strengths obey the power distribution, and 3) the fractured elements do not support any load. Then, the expression for $G(u)$ is written as

$$
G(u)=s_{0}[u /(1-G(u))]^{n}
$$

$s_{0}$ being the normalization factor. See Appendix A for the derivation of $G(u)$ in more detail.

The normalized shear stress $u$ is written by $u \cong r / r_{f}$, where $r$ is given by (1). $r_{f}$ denotes the shear strength of specimens and the equality holds when the cohesion can be neglected in the Coulomb's criterion. The model for Eq. (9) is called fracture process model. The experimental data show that tensile cracks are kept open even under high confining pressure. The expression (6) suggests that the stress concentrations around tips of shear cracks produced by shear fracture keep the tensile cracks open.

The behavior of $G(u)$ for $m=2$ is illustrated for example in Fig. 5(a). The function $G(u)$ yields the upper and the lower bound of the fracture density for a specimen sustaining the applied stress $u$. The hatched area enclosed by the curve $\mathrm{ABC}$ and the line $\mathrm{CA}$ indicates thus the realizable domain of $(u, G)$ in the specimen. The value of $u$ on the curve ABC means the fracture strength of the specimen of which the fracture density is $G$. The applied stress at B means thus the ultimate strength of the specimen. In the case of $G$ larger than $v_{c}$ in Fig. 5(a), rupture starts to propagate throughout the specimen just at the time when the increasing applied stress reaches to the stress on the curve $\mathrm{BC}$, provided that the 
a)

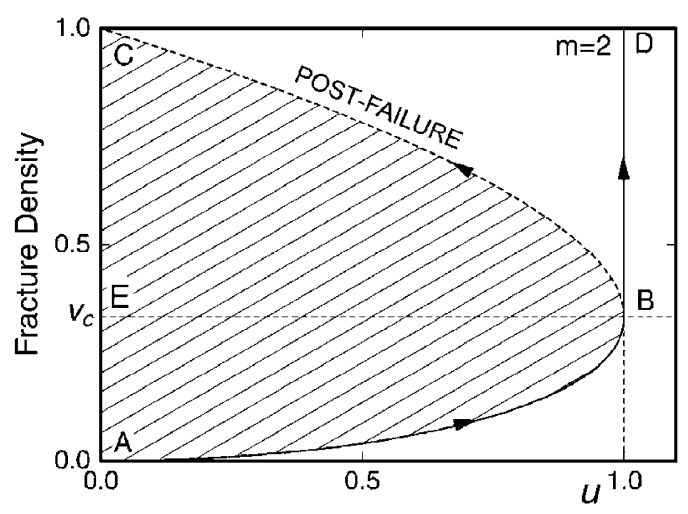

b)

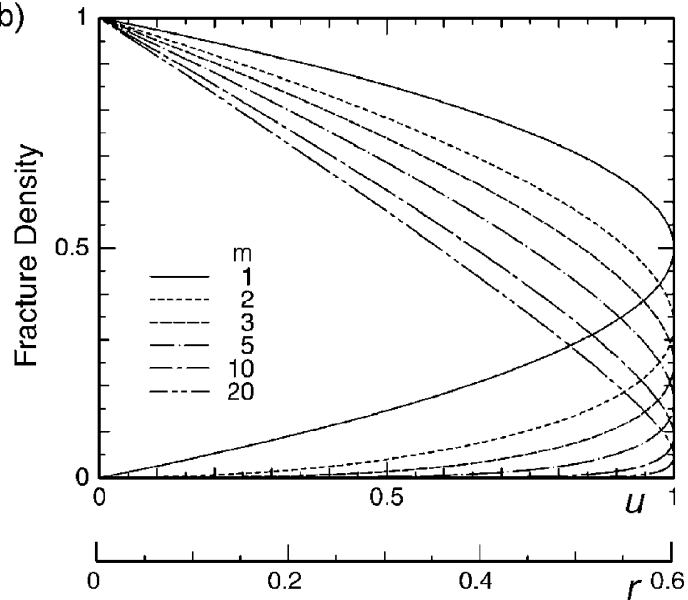

Fig. 5. Fracture density $G(u)$ as a function of applied shear stress $u$ divided by the ultimate shear strength. a) Explanation of $G(u)$. The stress at the point $\mathrm{B}$ means the ultimate fracture strength of a specimen. The path BD means that all volume loses the strength at once or the path for the macroscopic fracture. The path BC means the post-failure state. b) The behavior of the function $G(u)$ for some values of $m . r$ is the potential stress defined by (1) in the text.

loading system is elastic. The state on the curve $\mathrm{BC}$ can be exactly realized in laboratories, only when a completely rigid apparatus is used to apply the displacement to a specimen.

In the case of $G$ smaller than $v_{c}, G$ may increase tracing the curve $\mathrm{AB}$ with an increase in $u \approx r / r_{f}$ or $r$ for rock specimens that have suffered no damages. In the case of $G$ larger than $v_{c}$, a rock specimen has to deform until the applied stress decreases to the magnitude the specimen can sustain, that is the stress on the curve BC. The post-failure state means here the state on the curve BC. The applied displacement rather than the applied stress may control the stress in the rocks under the post-failure state.

4.2 Estimation of tensile crack density in damaged zone

Rocks in the damaged zone have been heavily damaged and have small compressive or shear fracture strength. The stress outside the zone should equilibrate to the strength of the zone, because the strength outside the zone is larger than that inside. These mean that the damaged zone is under the post-failure state. For the present analysis, it is assumed that the expression (9) is applicable throughout the range of fracture density $G$. This expression is derived from the unique principle throughout the range of $G$ that the strength distribution is expressed by a power function. For this reason, the assumption may be justifiable, although the expression has been experimentally confirmed to hold for $G$ smaller than $v_{c}$ or on the AB branch.

If the $r$-value is determined from the stresses near the damaged zone, the value of $G$ is determined for $u=r / r_{f}$, provided that the damaged zone is in the post-failure state. Figure 5(b) shows the function $G(u)$ calculated for some values of parameter $m$. The value of $m$ has been estimated to range roughly from 5 to 10 for some kinds of rocks and the crust (Yamamoto, 1998). Assuming that the shear strength of the rocks outside the damaged zone is represented by $r_{f}=0.6$, the fracture density $G(u)$ is estimated to be a value about 0.8 for the damaged zone where $r=0.2$. The density $c$ of tensile cracks at a depth can be estimated by making use of (7) or (8) on the assumption that the $r$-value is constant for depth. The applicability of the present model to dam- age zones should be confirmed by comparing the deductions from the model with the observed field data.

\subsection{Calculation of elastic constants}

The seismic wave velocities of damaged zones have been determined for some faults by seismic reflection profiling (e.g. Feng and McEvilly, 1983) and by analysis of trapped waves (e.g. Li et al., 1998, 2000; Nishigami, 2000; Kuwahara and Ito, 1999). Although the elastic property is naturally expected to be anisotropic from the crack orientation, the observations and the analyses have been performed, provided that zones are isotropic. For the comparison, we calculate the velocities of the zone for the crack density $c$ estimated by the above procedure on the assumption that the isotropic property stands for the averaged one. The elastic constants are calculated by making use of the method called new self-consistent scheme (NSC) proposed by Yamamoto et al. (1981) and Norris (1985).

It has been suggested in the preceding section that elastic anisotropy of damaged zone plays an important role on the shear strength of fault. Especially small rigidity and large Young's modulus to the stresses on the plane parallel to the fault are expected to bring about the large concentration of the shear stress relative at asperities to the normal stress. Such concentration of shear stress cannot be expected for the damaged zone where crack orientation is isotropic. For the reason, the elastic anisotropy of damaged zone is necessarily required to be known for the discussion of the strength of fault. The elastic constants of damaged zone are calculated by approximation method for weakly interacted inclusions (WIA) by Yamamoto (1980, 1995), assuming that the surface normals of cracks in damaged zones are parallel to the fault plane and orient symmetrically around the fault normal. The elastic property of damaged zone is thus symmetric around the $x_{1}$-axis (see Fig. 3(a)). The method of WIA is introduced in Appendix B. The precision of the method and the effects of crack shape and pore material have been introduced briefly in our previous paper (Yamamoto et al., 2001).

These methods, NSC and WIA are based on the theory 


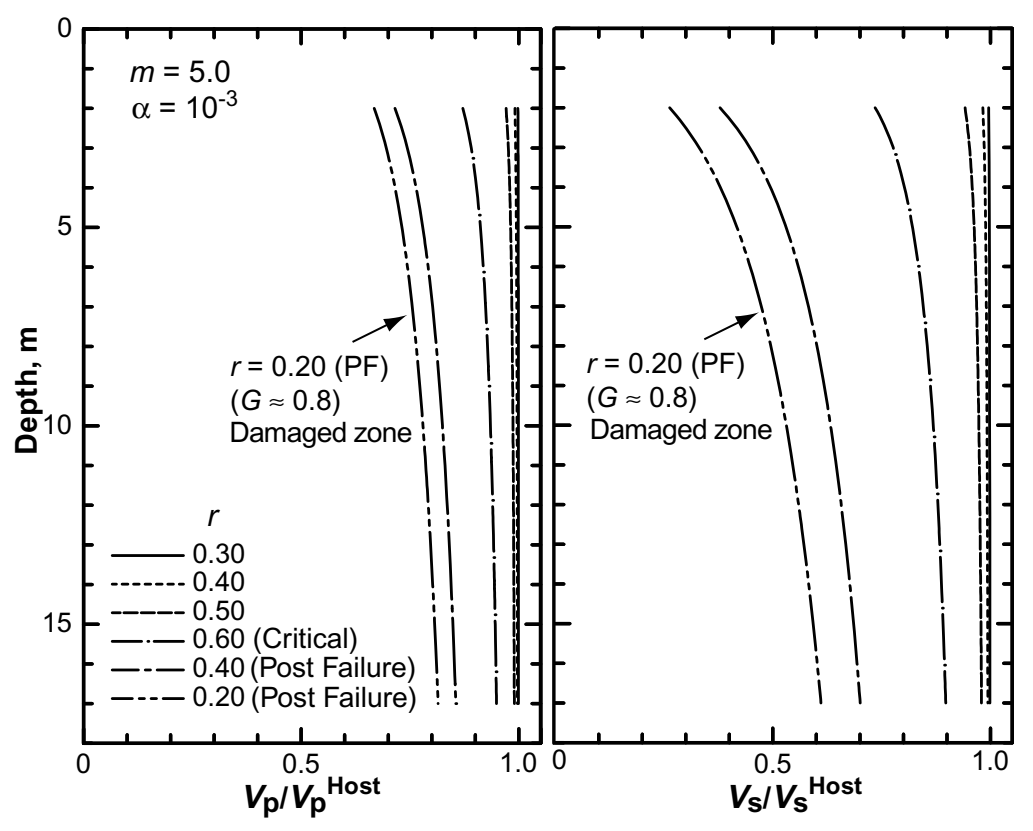

Fig. 6. P- and S-wave velocities of the crust subjected to the potential stress $r$. The each curve shows the ratio of the velocity at the depth to that of the host rock. The potential stress $r$ equal to 0.2 (Post-Failure) corresponds to that in the damaged zone.

of Eshelby (1957). The cracks are theoretically isolated from one another. Therefore, the deformation of the zone pressurizes the pore fluid in cracks, when the cracks are saturated with fluid. Even if the zone is permeable, it needs a time for fluid to transfer from a crack to other cracks, although the time for the transference is unknown. The fluid may be pressurized for the quick deformation of the zone such as caused by seismic waves, while the cracks may behave as if they are void for the slow deformation of the zone over years. In the present paper, the elastic wave velocities of damaged zone are calculated for the isolated cracks saturated with water, while its elastic response to tectonic stress change is done for the void cracks.

\section{Seismic Wave Velocities of Damaged Zone}

The fracture density $G$ has been estimated to be about 0.8 for the Nojima fault, as stated in the preceding section. Assuming that confining pressure and pore pressure respectively are lithostatic and hydrostatic, the crack density $c$ is determined as a function of depth by substituting $\rho_{\text {rock }}=2.7 \times 10^{3} \mathrm{~kg} / \mathrm{m}^{3}$ and $\rho_{\text {pore }}=1.0 \times 10^{3} \mathrm{~kg} / \mathrm{m}^{3}$ into (8). The seismic wave velocities are calculated for $c$ thus determined. The Poisson's ratio, the incompressibility and the density of the host rock respectively are taken to be $1 / 4,60$ $\mathrm{GPa}$, and $2.7 \times 10^{3} \mathrm{~kg} / \mathrm{m}^{3}$ in order to approximate the property of granite. The calculated velocities are shown in Fig. 6 as the ratios to those of the host rock, provided that the aspect ratio $\alpha$ of cracks is taken to be equal to $10^{-3}$.

The velocity ratio is about $70 \%$ for the $\mathrm{P}$-waves and about $33 \%$ for the S-waves at $3 \mathrm{~km}$ in depth. Although the velocities gradually increase with an increase in depth, the ratio is about $80 \%$ for P-waves and about $60 \%$ for S-waves at 15 $\mathrm{km}$ in depth. Li et al. (1998), Kuwahara and Ito (1999), and Nishigami (2000) have observed the waves that propagate being trapped along a fault. They estimated the width and the elastic property of the wave-guide. According to them, the width is about 20 to $50 \mathrm{~m}$ and the velocity of S-waves is 40 to $66 \%$ of that outside the wave-guide. Li et al. (2000) also obtained the S-wave velocity structure of the Landers fault zone from trapped waves. They determined the velocity to be from $55 \%$ to $69 \%$ of the S-wave velocity of the host rock for the depth from 1 to $10 \mathrm{~km}$. Their observed velocity appears to be larger by about $10 \%$ than that of the present estimate at the Nojima fault.

One easy way to diminish the disagreement in the case of the Landers fault zone may be to reduce the fracture density. Li et al. (1998) have pointed out that the ratio of the travel time of P-waves to that of S-waves recovered after the 1992 Landers, California, earthquake cannot be explained well by the theory for isotropic orientation of cracks. This ratio may imply the anisotropy in the elastic property of damaged zone. Taking such ambiguities in fracture density and anisotropy into consideration, it is not considered that the disagreement is definitive. Taking account of the results by Li et al. (1998), Kuwahara and Ito (1999) and by Nishigami (2000) together, the S-wave velocity estimated by the present model appears to approximate to the observed one of damaged zone. For the further discussion in detail, the anisotropy should be taken into consideration.

McGarr et al. (1982) reviewed the in-situ stresses near the San Andreas Fault in the Mojave Desert. The site MOJ1 at the nearest to the San Andreas Fault is about $2 \mathrm{~km}$ distant from the fault. The measurement was performed to $218 \mathrm{~m}$ deep at the greatest at this site. The values of $r$ calculated for the stress data are about 0.19 to 0.21 at depths larger than $100 \mathrm{~m}$. These $r$-values are close to those for the damaged zone of the Nojima fault. We assume that this small $r$-value is caused by the small strength of the damaged zone of the San Andreas Fault, although more stress measurements are required to conclude this. On this assumption, the fracture 


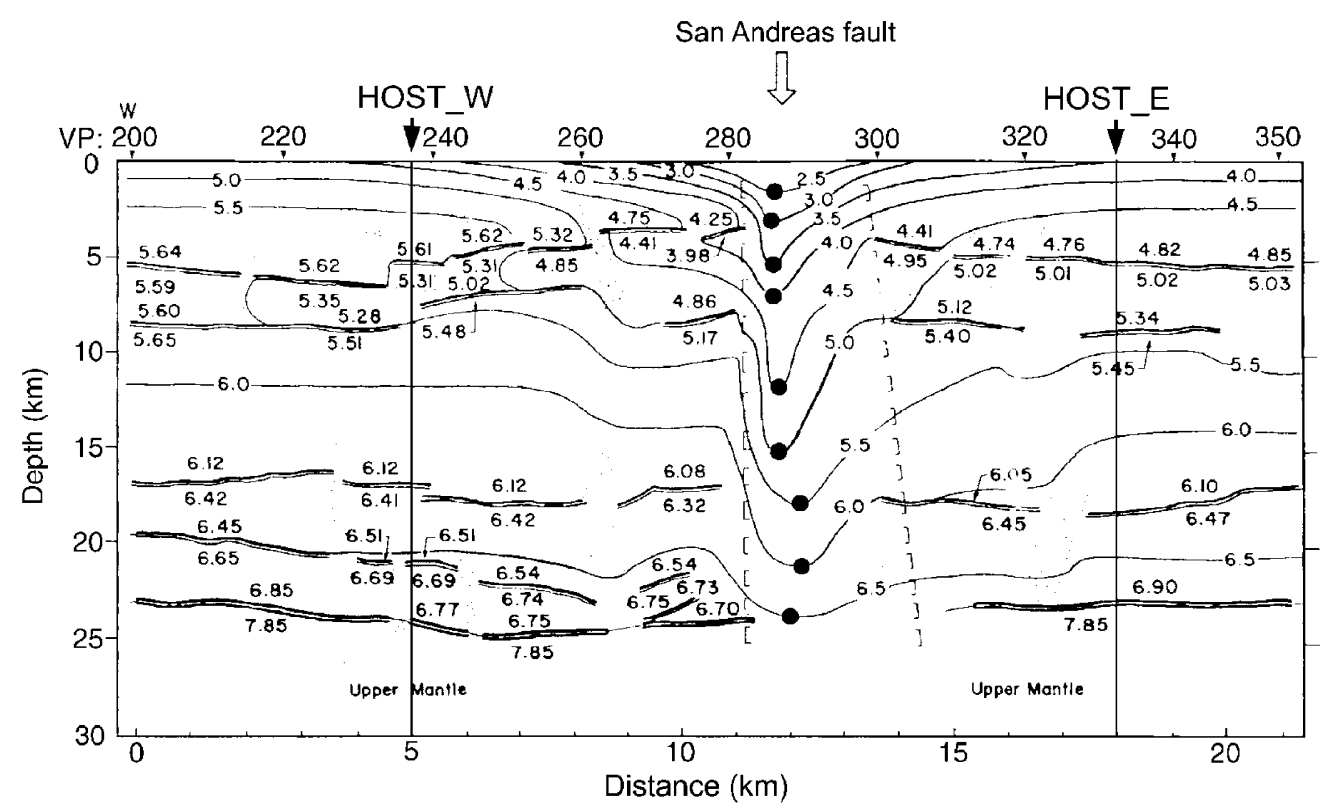

Fig. 7. P-wave velocities of the damaged zone and the host rock shown on the P-wave velocity structure determined by Feng and McEvilly (1983). Solid circles indicate the P-wave velocities at the depths taken as those of the damaged zone to be compared with the calculated ones, and the velocities at the points where the lines HOST_E and HOST_W intersect the velocity contours are taken as the velocities of the host rock for the calculation. The figure is modified from Feng and McEvilly (1983).

density is inferred to be about 0.8 for the San Andreas Fault as well as the Nojima fault.

Feng and McEvilly (1983) interpreted seismic reflection profiling data to get the P-wave velocity structure of the San Andreas Fault zone. Figure 7 shows the structure they have determined. It is seen that the low velocity zone reaches the depth of about $25 \mathrm{~km}$ and the velocity in the fault zone decreases to about $65 \%$ of the velocity outside the fault zone at the smallest. Here, the smallest velocity is regarded as the velocity of damaged zone. Assuming that the velocities on the lines denoted by HOST_W and HOST_E in Fig. 7 are the velocities of the host rocks at the depths, the velocities of the damaged zone are calculated for the host rocks by using the velocity ratio calculated for $G=0.8$, that is shown in Fig. 6 . The velocities of the damaged zone thus estimated are shown in Fig. 8. Solid circle indicates the observed velocity. Square and diamond respectively denote the calculated ones for HOST_W and for HOST_E.

It is found that the calculated velocities are nearly equal to the observed ones for the depth smaller than about $15 \mathrm{~km}$. This calculation was performed for hydrostatic pore pressure as described earlier, provided that the fracture density is constant for depth. The coincidence of the calculated velocity with the observed one suggests that the P-wave velocity of the damaged zone of the San Andreas Fault is explained by the fracture process model and no pressurized or sealed fluid is required for the explanation. In order to keep the tensile cracks open under pressure at depth, the stress but for high pore pressure is needed. Shear fractures in the damaged zone may have been produced under the compressive stress nearly vertical to the fault plane. The stress concentration caused by the shear fractures keeps tensile cracks open as suggested from the tensile cracks in rock specimens under tri-axial compression test. This may be one of the proofs to

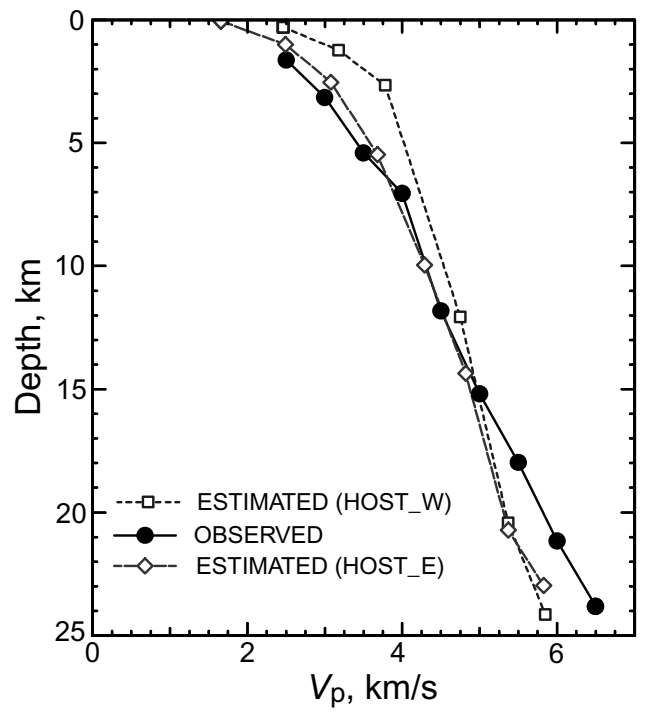

Fig. 8. Comparison of the estimated P-wave velocity with observed one for the damaged zone of the San Andreas Fault shown in Fig. 7. Circles, rectangles and diamonds indicate the observed velocities, the estimated velocities from the host rocks on the line HOST_W, and those on the line HOST_E, respectively.

justify the application of the fracture process model to damaged zones.

\section{Discussion on Shear Strength of Fault}

The Cartesian coordinate defined in Fig. 3(a) is employed for the definition of the elastic constants of damaged zone. Here, $E_{i i}$ denotes the stiffness for the relationship between $e_{i i}$ and $\tau_{i i}$, and $\mu_{i j}$ is the rigidity for the relationship between $e_{i j}$ and $\tau_{i j}$. We denote the shear stress, $\tau_{12}\left(=\tau_{13}\right)$, on the fault plane by $\tau$ and the normal stress, $\sigma_{11}$, to the fault plane 
by $\sigma$. Then, the strength of fault may be expressed in terms of $\tau / \sigma$, as described in the previous section. We define $\gamma$ as follows;

$$
\gamma \equiv \Delta(\tau / \sigma)_{\mathrm{ASP}} / \Delta(\tau / \sigma)_{\mathrm{TCT}}
$$

where $\Delta(\tau / \sigma)_{\text {ASP }}$ indicates the variation of the potential stress at asperities and $\Delta(\tau / \sigma)_{\mathrm{TCT}}$ is that of the tectonic potential stress. This index $\gamma$ means the concentration rate of the potential stress at asperities for an increase in the tectonic potential stress.

If the shear strength of the asperities is constant, the shear strength of faults may be proportional to $\gamma^{-1}$, provided that the fracture of asperities means the fracture of the fault. If the fraction $S$ of asperity areas to the whole fault plane area is negligibly small, the average elastic shear strain on the fault plane may be approximately equal to $\tau_{\mathrm{TCT}} / \mu_{12}$ or 13. Since the strain at asperities is considered to be nearly equal to this strain, the shear stress at asperities is expressed by

$$
\Delta \tau_{\mathrm{TCT}} \mu_{\mathrm{HOST}} / \mu_{12} \text { or } 13 \text {. }
$$

By the similar way, the normal stress at asperities is expressed by $\Delta \sigma_{\mathrm{TCT}} E_{\mathrm{HOST}} / E_{11}$, where $\mu_{\mathrm{HOST}}$ and $E_{\mathrm{HOST}}$ are the rigidity and the Young's modulus of the host rock, respectively. Therefore, the ratio $\gamma$ is expressed by

$$
\gamma \approx\left(\mu_{\mathrm{HOST}} / \mu_{12 \text { or } 13}\right) /\left(E_{\mathrm{HOST}} / E_{11}\right) \equiv \gamma^{\prime} .
$$

The ratio $\gamma$ cannot directly be known. The index $\gamma^{\prime}$ defined by (11) is employed standing for $\gamma$ to estimate the strength of fault on the assumption that the fraction $S$ of asperity area is negligibly small. The ratio $\gamma^{\prime}$ is here called as the concentration index of potential stress.

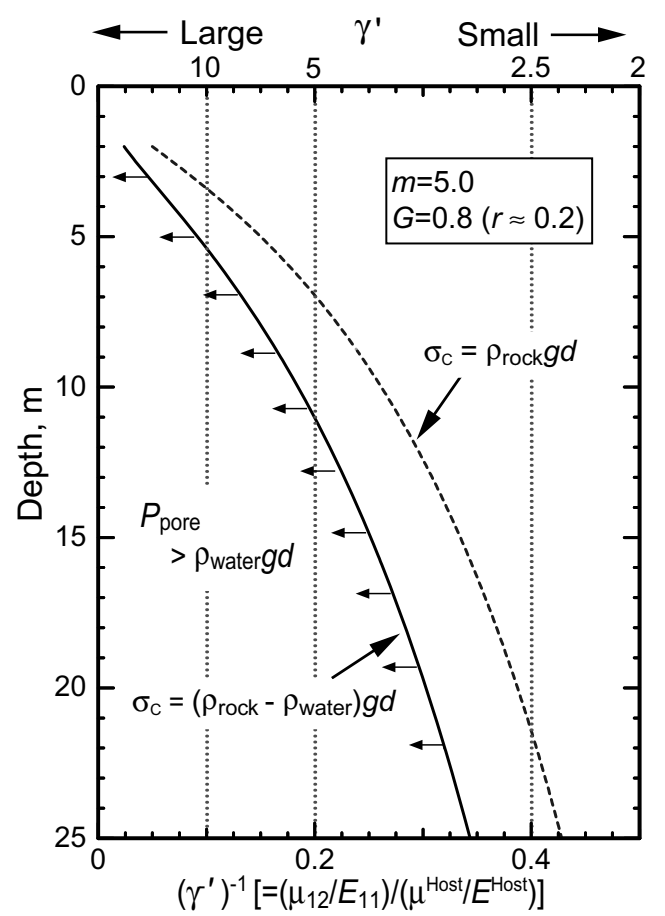

Fig. 9. The variation of the concentration index $\gamma^{\prime}$ with depth. See the text for the definition of $\gamma^{\prime}$. The solid and dash lines respectively indicate the hydrostatic pore pressure and the void cracks. The domain indicated by small arrows are the range of $\gamma^{\prime}$ when fluid in cracks is pressurized or sealed.
The Young's modulus $E_{11}$ and the rigidity $\mu_{12}$ or 13 of the fracture zone are calculated making use of WIA for void cracks of their aspect ratio $\alpha$ equal to $10^{-3}$. Figure 9 shows $\gamma^{\prime-1}$ as a function of depth for the fracture density $G=0.8$ $(r \approx 0.2)$, which has been determined for the damaged zone of the Nojima fault. Solid curve denotes the case of the hydrostatic pore pressure and dash curve does the case of the void cracks. The value of $\gamma^{\prime}$ should be larger than that of the solid curve, if the damaged zone is hydraulically impermeable. When the pore-pressure in the cracks is hydrostatic, the value of $\gamma^{\prime}$ is larger than 10 at small depths and decreases with an increase in depth to about 4 at the depth of $15 \mathrm{~km}$. Although the shear strength of fault becomes larger with an increase in depth, the strength can be about 0.15 in terms of $\mu$ even at the depth of $15 \mathrm{~km}$, provided that $\mu$ is taken to be 0.6 for host rocks. It may be concluded that faults can be weak in the upper crust even without pressurized or sealed fluid in damaged zones.

\section{Summary}

The Nojima fault in Awaji Is., Hyogo prefecture, Japan, ruptured during the 1995 Hyogo-ken Nanbu earthquake $\left(M_{\mathrm{JMA}}=7.3\right)$. Stresses have been measured at sites close to this fault. The measurements have revealed that the maximum horizontal stress is almost perpendicular to the strike of this nearly vertical fault at all the sites except for shallow depths at a site. These orientations of stress suggest that the Nojima fault is weak, although this fault is not located at a plate boundary.

The other important result is that in the zone within about $100 \mathrm{~m}$ from the fault core axis, the shear stress is very small compared with that at a distance from the fault. It can be concluded that the principal direction of stress perpendicular to the fault plane results from the small shear stress in the zone. It is considered that the rocks near the fault core have been heavily damaged to have small compressive or shear strength. The small shear stress measured near fault core can be interpreted thus as the reflection of the small shear strength of damaged zone.

Some problems seem however to be left in order to conclude that the fault is weak from the macroscopic viewpoint. One of them is that the stress measurements have been limited at shallow depths. Another is that the measurements have not been performed uniformly and densely along the fault. It may be also the problem that the mechanism to weaken faults is unclear. The main aims of the present paper are to derive the answers to these problems based on the above results of the stress measurements.

Damaged rocks have not only small fracture strength but also small elastic constants. If a fault is locked from the macroscopic viewpoint and the fault plane consists of asperities and damage zone, the shear strength of the fault will be controlled by the stress concentration at asperities, which may be brought about by deformation of damaged zone. It is thus important to determine the elastic constants of damaged zone. The elastic property is also important for the investigation of the stress state in damaged zones at great depths that cannot be known by the direct stress measurement.

A model called the fracture process model is introduced to estimate the density of tensile cracks in damaged zone 
from the measured stresses near the zone. The theoretical method called NSC has been established to calculate the elastic wave velocities of cracked media. Making use of the fracture process model and the NSC method, the elastic wave velocities of damaged zone are estimated from the stresses measured near the Nojima fault.

The seismic wave velocities are calculated on the assumptions that the ratio $r$ of the maximum shear stress to the normal stress is constant at 0.2 throughout depth and that the damaged zone is hydraulically permeable. Further, these assumptions are presumed to hold for every fault for the comparison of the estimated results with the field data. The calculated velocity for P-waves is found to explain almost completely the smallest velocity at the center of the San Andreas Fault zone to about $15 \mathrm{~km}$ in depth. Although the calculated S-wave velocity explains the observed one not so completely as that of P-waves, the observed seismic wave velocities that are consistent with the calculated ones suggest that damaged zone is hydraulically permeable in the upper crust.

The ratio $\gamma$ of shear stress concentration to normal stress concentration at asperities is theoretically estimated from the elastic anisotropy of damaged zone on the assumption that asperities occupy the negligibly small area of fault plane. The ratio is estimated to be larger than 10 for about $3 \mathrm{~km}$ deep and approximately 4 for $15 \mathrm{~km}$ deep. These results imply that the shear strength of fault can be smaller than 0.15 in terms of friction coefficient. The pressurized fluid may not be essential for weak faults in this context, although the pressurized fluid might play an important role on the propagation of rupture.

Acknowledgments. Prof. M. Ando, Kyoto University*, provided our stress measurement in the program for the research of earthquake fault by drilling. Dr. K. Takemura, Kyoto University, prepared core samples for our measurement. Dr. H. Ito and Dr. Y. Kuwahara, Geological Survey of Japan**, readily permitted us to use the core samples of Ikuha and Hirabayashi for our measurement. Prof. Tsukahara, Shinsyu Univ. and Dr. Ikeda, NEID***, prepared us the results of their stress measurements. Further, the discussions with them and the suggestions from them are very useful to progress this study. We have to thank all of them for their helpful support to this study. We would like to express special thanks to emeritus Prof. Hirasawa, Tohoku University, for his suggestive comments and introductions on the problems included in the process of faulting. The suggestions and the advices from Dr. Iio and an anonymous reviewer are very helpful for us to improve this manuscript. We also express very much thanks to them. (*Nagoya Univ. at present; ${ }^{* *}$ National Institute of Advanced Industrial Science and Technology, ${ }^{* * *}$ Hokkaido Univ. at present).

\section{Appendix A. Fracture Process Model}

We consider a rock specimen subjected to an axial stress under confining pressure. It is assumed that the specimen consists of small volume elements called physical elements as shown in Fig. A.1. Further, the element volume is assumed to be a characteristic constant proper to the rock. The element volume can be taken thus to be a measure of specimen volume.

When one of physical elements fractures by an increment in applied axial stress, the rupture started at the element propagates over some numbers of physical elements to form a fault plane. The strain energy stored in the volume surrounding the plane may be released and the physical elements in the volume may lose their strengths by the faulting. We may reasonably to consider that the volume and the fault plane are approximately identical in linear dimension. The volume is called a microfracture element. The strength of a microfracture element is thus identical to the strength of the weakest physical elements in the microfracture element.

It is assumed that a microfracture element consists of $q$ physical elements. When the strength distribution function is represented by $P_{e}\left(u_{s}\right)$ for the physical elements, the strength distribution function $P\left(u_{s}\right)$ for microfracture elements may be expressed by

$$
P\left(u_{s}\right)=1-\left[1-P_{e}\left(u_{s}\right)\right]^{q}
$$

(e.g. Freudenthal, 1968). Here, the strength $u_{s}$ is defined in the range where $P_{e}\left(u_{s}\right)$ and $P\left(u_{s}\right)$ have the values between 0 and unity. When the distribution function $P_{e}\left(u_{s}\right)$ is expressed by a power function,

$$
P_{e}\left(u_{s}\right)=s u_{s}^{m},
$$

$P\left(u_{s}\right)$ may be written by

$$
P\left(u_{s}\right) \approx q s u_{s}^{m} .
$$

Here, we redefine the strength distribution function for microfracture elements to be

$$
P\left(u_{s}\right)=s_{0} u_{s}^{m}
$$

where

$$
s_{0} \approx q s .
$$

When the fractured volume has completely lost their strength $\left(k^{\prime}=0\right.$ in Fig. A.2), the load to a specimen should be sustained by the potential microfracture elements. For a specimen where the fractured volume fraction is expressed by $G(u)$ at the applied stress $u$, the stress $u_{e}$ in the potential elements may be expressed by

$$
u_{e}=\frac{u}{1-G(u)} .
$$

The volume fraction $G(u)$ and the stress $u_{e}$ are called the fracture density and the effective stress, respectively.

When applied stress $u$ is increased from 0 to $u$, the effective stress is increased from 0 to $u_{e}$ and the elements of their strength smaller than $u_{e}$ have been fractured. Since the volumes are the same for all microfracture elements, $G(u)$ may be expressed by

$$
G(u)=P\left(u_{e}\right)=s_{o}\left[\frac{u}{1-G(u)}\right]^{m} .
$$

This function $G(u)$ is a two valued function of $u$. The largest value of $u$, that is the ultimate strength $u_{f}$ of the specimen, is derived from $d u / d G=0$ as

$$
\begin{aligned}
& u_{f}=\left(1-v_{c}\right) v_{c}^{1 / m}\left(s_{o}\right)^{-1 / m} \\
& v_{c}=1 /(1+m) .
\end{aligned}
$$

The ultimate strength $u_{f}$ of a specimen is attained at $G=v_{c}$, $v_{c}$ is called the critical volume fraction for fracture. Using (A.4), the ultimate strength $u_{f}$ is written by

$$
u_{f} \approx\left(1-v_{c}\right) v_{c}^{1 / m}(q s)^{-1 / m} .
$$


SPECIMEN

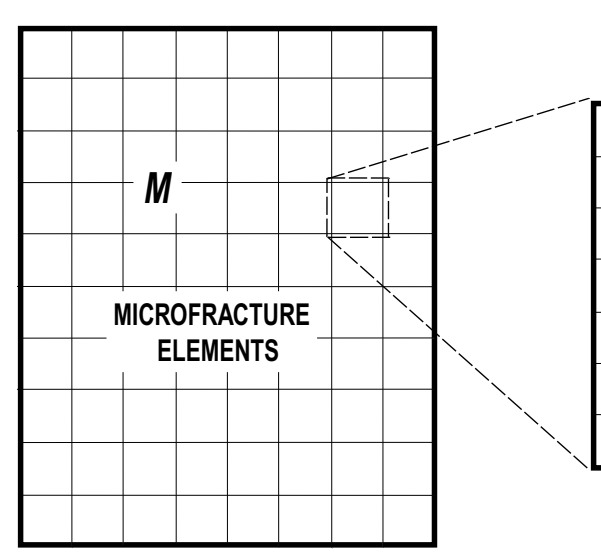

MICROFRACTURE ELEMENT

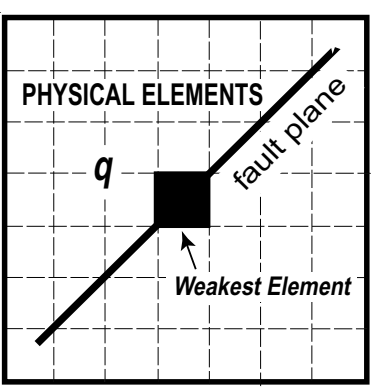

Fig. A.1. Schematic illustration of a rock specimen modeled for explanation of the fracturing process. A specimen consists of $M$ microfracture elements and a microfracture element consists of $q$ physical elements. Rupture started at a physical element propagates over a number of physical elements to form a microfracture element.

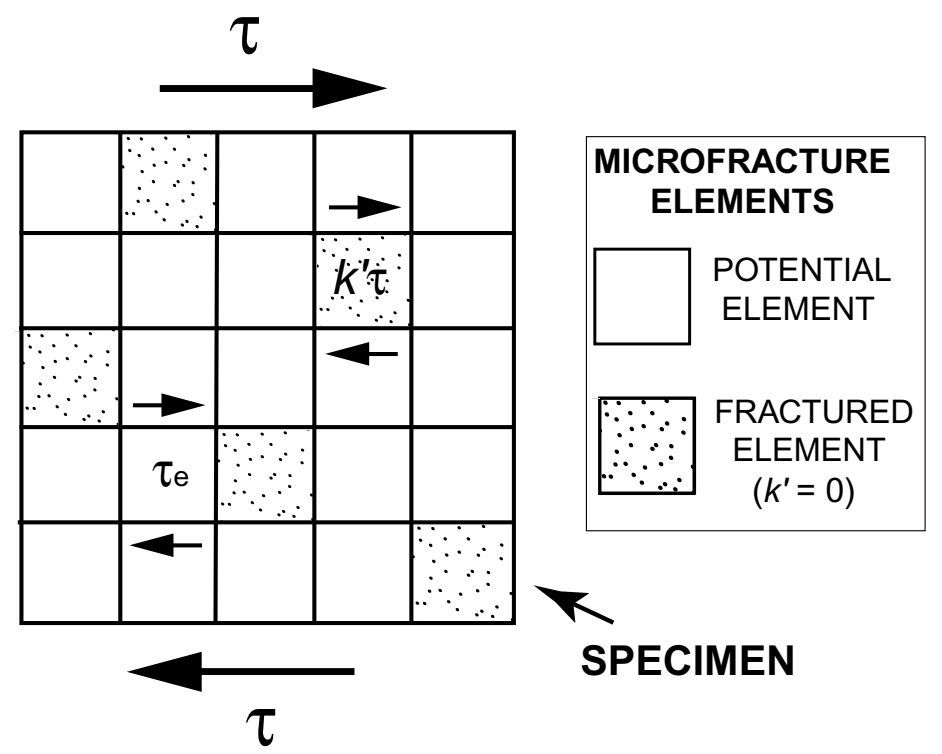

Fig. A.2. Illustration for explanation of effective stress $\tau_{e}$. Potential elements mean the microfracture elements that have not been fractured under the stress $\tau$ applied to specimen. $k^{\prime} \tau$ indicates the stress in fractured elements remaining after fracturing. $k^{\prime}=0$ represents the complete loss of strength.

Since $q$ represents the size of microfracture elements, this expression means that the ultimate strength $u_{f}$ decreases with an increase in the size of microfracture. The expression means that the ultimate strength decreases, when the microfracture size increases with an increase in specimen size. Therefore, Eq. (A.8) expresses the size effect of ultimate strength.

The function $G(u)$ represents the process to the macroscopic fracture and yields the definition of ultimate strength in terms of the strength distribution for microfractures when applied stress is increased up to $u_{f}$. The fracture process model means the model used for the derivation of the function $G(u)$.

\section{Appendix B. Weak Interaction Approximation (WIA)}

Basic Equations
We denote strain component by $e_{p}$ and stress component by $\tau_{q}$, elastic constants and elastic compliances, respectively, by $C_{q p}$ and $S_{p q}$, where $p, q=1-6$. When we express strain and stress fields, respectively, by

$$
\mathbf{e}=\left\{e_{p}\right\} \text { and } \boldsymbol{\tau}=\left\{\tau_{q}\right\},
$$

the stress-strain relationship is written by

$$
\boldsymbol{\tau}=\mathbf{C e} \quad \text { or } \mathbf{e}=\mathbf{S} \boldsymbol{\tau},
$$

where

$$
\mathbf{C}=\left\{C_{p q}\right\} \quad \text { and } \quad \mathbf{S}=\left\{S_{q p}\right\} .
$$

We consider a composite in which $k$ inclusions are embedded in homogeneous isotropic matrix. When the strain and the stress averaged over the composite are denoted by $\mathbf{e}^{a}$ and 
$\boldsymbol{\tau}^{a}$, respectively, $\mathbf{e}^{a}$ and $\boldsymbol{\tau}^{a}$ may be written by

$$
\begin{aligned}
\mathbf{e}^{a} & =(1-v) \mathbf{e}_{k}^{M}+\sum_{j=1}^{k} v_{j} \mathbf{e}_{j}^{I} \\
\boldsymbol{\tau}^{a} & =(1-v) \boldsymbol{\tau}_{k}^{M}+\sum_{j=1}^{k} v_{j} \boldsymbol{\tau}_{j}^{I} .
\end{aligned}
$$

The strain e and the stress $\tau$ with superscript $M$ or $I$ mean the strain and the stress averaged over matrix or an inclusion. The subscript $j$ indicates the quantities of the $j$ th inclusion. $v_{j}$ is the volume fraction of the $j$ th inclusion. The total volume fraction of inclusions $v$ is thus written by

$$
v=\sum_{j=1}^{k} v_{j}
$$

The following expressions are derived from (B.1);

$$
\begin{aligned}
& \mathbf{e}^{a}=\mathbf{e}^{u}+\sum_{j=1}^{k} v_{j} \mathbf{e}_{j}^{P}, \\
& \text { where } \quad \mathbf{e}_{j}^{P}=-\left(\mathbf{S}_{j}^{I}-\mathbf{S}^{M}\right) \boldsymbol{\tau}_{j}^{I} \text { and } \mathbf{e}^{u}=\mathbf{S}^{M} \boldsymbol{\tau}^{a} \\
& \boldsymbol{\tau}^{a}=\boldsymbol{\tau}^{u}+\sum_{j=1}^{k} v_{j} \boldsymbol{\tau}_{j}^{P}, \\
& \text { where } \quad \boldsymbol{\tau}_{j}^{P}=\left(\mathbf{C}_{j}^{I}-\mathbf{C}^{M}\right) \mathbf{e}_{j}^{I} \text { and } \boldsymbol{\tau}^{u}=\mathbf{C}^{M} \mathbf{e}^{a}
\end{aligned}
$$

and

$$
\mathbf{e}_{j}^{P}=\mathbf{S}^{M} \boldsymbol{\tau}_{j}^{P} \quad \text { and } \quad \boldsymbol{\tau}_{j}^{P}=\mathbf{C}^{M} \mathbf{e}_{j}^{P} .
$$

Here, $\mathbf{e}_{j}^{P}$ and $\boldsymbol{\tau}_{j}^{P}$ are the polarization strain and the polarization stress, respectively (Hill, 1963). $\mathbf{e}^{u}$ and $\boldsymbol{\tau}^{u}$ are the uniform strain and the uniform stress in the matrix that is presumed to fill up the composite. When the displacements are given at the outer boundary of the composite, the average strain field in a composite should satisfy the upper equation of (B.2) and when the traction is applied to the outer boundary, the average stress field in a composite should satisfy the lower equation of (B.2).

The strain energy density $W$ is generally defined by

$$
W=\frac{1}{2} \int_{V}(\boldsymbol{\tau}(\mathbf{x}) \cdot \mathbf{e}(\mathbf{x})) d v,
$$

$\mathbf{x}$ being the position in the composite. Denoting the strain energy density for the displacement condition by $W_{s}$ and that for the stress condition by $W_{c}$. For the composite whose effective elastic constants are $\mathbf{C}^{k}$ and $\mathbf{S}^{k}$, the strain energy densities may be expressed by

$$
\begin{aligned}
2 W_{s}^{k} & =\left(\mathbf{e}^{a} \cdot \mathbf{C}^{k} \mathbf{e}^{a}\right) \\
& =\left(\mathbf{e}^{a} \cdot \mathbf{C}^{M} \mathbf{e}^{a}\right)+\sum_{j}^{k} v_{j}\left(\mathbf{e}^{a} \cdot \mathbf{C}^{M} \mathbf{e}_{j}^{p}\right) \\
2 W_{c}^{k} & =\left(\boldsymbol{\tau}^{a} \cdot \mathbf{S}^{k} \boldsymbol{\tau}^{a}\right) \\
& =\left(\boldsymbol{\tau}^{a} \cdot \mathbf{S}^{M} \boldsymbol{\tau}^{a}\right)+\sum_{j}^{k} v_{j}\left(\boldsymbol{\tau}^{a} \cdot \mathbf{S}^{M} \boldsymbol{\tau}_{j}^{p}\right) .
\end{aligned}
$$

The equations (B.4) hold for macroscopically uniform composites, when there are no body forces and no internal stresses in the composite (see Watt et al., 1976). The second terms in the right hand sides of (B.4) correspond to the interaction energy defined by Eshelby (1957).

Method for Approximation

It is assumed that there is a preexisting composite, of which the elastic constants are known to be $\mathbf{C}^{k}$. We consider the case that a matrix part of the composite is replaced with a number of inclusions under the displacement condition. Here, the volume fraction of newly introduced inclusions is indicated by $v_{k+1}$. If $v_{k+1}$ is so small that the variation in strain in preexisting matrix and inclusions are negligibly small, the strain energy $W_{s}^{k+1}$ after this replacement may be written as

$$
\begin{aligned}
2 W_{s}^{k+1} & =\left(\mathbf{e}^{a} \cdot \mathbf{C}^{k+1} \mathbf{e}^{a}\right) \\
& \approx\left(\mathbf{e}^{a} \cdot \mathbf{C}^{k} \mathbf{e}^{a}\right)+v_{k+1}\left(\mathbf{e}^{a} \cdot \mathbf{C}^{M} \mathbf{e}_{k+1}^{p}\right) .
\end{aligned}
$$

Here, $\mathbf{e}_{k+1}^{P}$ is the polarization strain. The elastic constants $C^{k+1}$ after the replacement may be thus determined by evaluating $\mathbf{e}_{k+1}^{p}$.

In principle, $\mathbf{e}_{k+1}^{p}$ cannot be determined without solving the deformation of matrix and inclusions in newly produced composite under the displacement condition. However, it is not the present task to solve this problem. Eshelby (1957) presented the expression for the strain in a spheroidal inclusion embedded in infinite isotropic matrix strained by $\mathbf{e}^{a}$. He yielded further the polarization strain or the stress free strain $\mathbf{e}^{p}$ in the following form,

$$
\mathbf{e}^{p}=-\mathbf{T e}^{a} .
$$

The expressions for $\mathbf{T}$ are given in his paper. We employ his solution as that for the finite size of composite in the expectation that the precision of the solution gradually drops with an increase in volume fraction of inclusions.

We assume here that the spheroidal inclusions have the same elastic property and the same shape and are oriented to the same direction. It may be rational to consider that the matrix to be newly replaced with the inclusions is strained by $\mathbf{e}_{k}^{u}$ for the polarization strain $\mathbf{e}_{k+1}^{p}$, as seen from (B.2). Using the expression for $\mathbf{e}^{u}$ in (B.2) and $\mathbf{C}^{k}, \mathbf{e}_{k+1}^{p}$ may be expressed by

$$
\mathbf{e}_{k+1}^{p}=-\mathbf{T} \mathbf{S}^{M} \mathbf{C}^{k} \mathbf{e}^{a} .
$$

Making use of (B.7), we can derive the following expressions,

$$
\begin{aligned}
\left(\mathbf{e}^{a} \cdot \mathbf{C}^{k+1} \mathbf{e}^{a}\right) & =\left(\mathbf{e}^{a} \cdot \mathbf{C}^{k} \mathbf{e}^{a}\right)-v_{k+1}\left(\mathbf{e}^{a} \cdot \mathbf{C}^{M} \mathbf{T} \mathbf{S}^{M} \mathbf{C}^{k} \mathbf{e}^{a}\right) \\
& =\left(\mathbf{e}^{a} \cdot \mathbf{C}^{M}\left(\mathbf{I}-v_{k+1} \mathbf{T}\right) \mathbf{S}^{M} \mathbf{C}^{k} \mathbf{e}^{a}\right)
\end{aligned}
$$

on the condition that $v_{k+1}$ is sufficiently small. Equating the coefficients of $e_{i}^{a} e_{j}^{a}$ on the both sides of the equation, the effective elastic constants $\mathbf{C}^{k+1}$ are determined as follows;

$$
\begin{aligned}
\left\{\mathbf{C}^{k+1}\right\}_{i j}=\frac{1}{2}[ & {\left[\mathbf{C}^{M}\left(\mathbf{I}-v_{k+1} \mathbf{T}\right) \mathbf{S}^{M} \mathbf{C}^{k}\right\}_{i j} } \\
& \left.+\left\{\mathbf{C}^{M}\left(\mathbf{I}-v_{k+1} \mathbf{T}\right) \mathbf{S}^{M} \mathbf{C}^{k}\right\}_{j i}\right] .
\end{aligned}
$$

From the stress condition, we obtain

$$
\begin{aligned}
\left\{\mathbf{S}^{k+1}\right\}_{i j}=\frac{1}{2}[ & \left\{\left(\mathbf{I}+v_{k+1} \mathbf{T}\right) \mathbf{S}^{M} \mathbf{C}^{M} \mathbf{S}^{k}\right\}_{i j} \\
& \left.+\left\{\left(\mathbf{I}+v_{k+1} \mathbf{T}\right) \mathbf{S}^{M} \mathbf{C}^{M} \mathbf{S}^{k}\right\}_{j i}\right] .
\end{aligned}
$$


By successive use of (B.9) or (B.10) and

$$
v=\sum_{j=1}^{k} v_{j}+v_{k+1},
$$

for $j$ from 1 to $k+1$, we can determine the effective elastic constants of composites with the inclusions oriented to the same direction. It has been confirmed that the same effective elastic constants are determined either from (B.9) or (B.10). Application to Arbitrarily Oriented Inclusion

The tensor $\mathbf{T}$ is represented in the coordinate system that is taken parallel to the principal directions of a spheroid that is defined as the shape of each inclusion. Here, we denote (strain, stress) in the coordinate of an inclusion by $\left(\mathbf{e}^{\prime}, \boldsymbol{\tau}^{\prime}\right)$, and (strain, stress) in the coordinate taken to the composite by $(\mathbf{e}, \boldsymbol{\tau})$. For the inclusion of which orientation is specified to the coordinate taken to the composite by $(\vartheta, \varphi),\left(\mathbf{e}^{\prime}, \boldsymbol{\tau}^{\prime}\right)$ may be related to $(\mathbf{e}, \boldsymbol{\tau})$ by

$$
\mathbf{e}^{\prime}=\mathbf{L}(\vartheta, \varphi) \mathbf{e} \quad \text { and } \quad \boldsymbol{\tau}^{\prime}=\mathbf{L}(\vartheta, \varphi) \boldsymbol{\tau}
$$

where $\mathbf{L}(\vartheta, \varphi)$ is the matrix for the transformation of tensor. For an inclusion of which orientation is specified by $(\vartheta, \varphi)$, the expression (B.7) may be rewritten as

$$
\mathbf{e}_{k+1}^{\prime p}=-\mathbf{T S}^{M} \mathbf{L}(\vartheta, \varphi) \mathbf{C}^{k} \mathbf{e}^{a}
$$

We consider the case that a number of inclusions are replaced with matrix at the $(k+1)$ th step of iteration. If the total volume $v_{k+1}$ of the newly introduced inclusions is very small and the distribution of the orientation is given by $\Phi(\vartheta, \varphi)$, Eq. (B.8) may be expressed by

$$
\begin{aligned}
& \left(\mathbf{e}^{a} \cdot \mathbf{C}^{k+1} \mathbf{e}^{a}\right)=\left(\mathbf{e}^{a} \cdot \mathbf{C}^{k} \mathbf{e}^{a}\right) \\
& \quad-v_{k+1} \int \Phi(\vartheta, \varphi)\left(\mathbf{L}(\vartheta, \varphi) \mathbf{e}^{a} \cdot \mathbf{P L}(\vartheta, \varphi) \mathbf{C}^{k} \mathbf{e}^{a}\right) d \vartheta d \varphi \\
& \mathbf{P} \equiv \mathbf{C}^{M} \mathbf{T S}^{M} .
\end{aligned}
$$

Equating the coefficients of $e_{i}^{a} e_{j}^{a}$ on the both sides of the equation, we can get the approximate values of the effective elastic constants of composite having arbitrarily oriented inclusions in isotropic matrix. The second term on the right hand side of (B.13) yields the increment of the effective elastic constants $\left\{d C_{i j}^{k}\right\}$. In order to yield explicit formulae, we take $x_{3}^{\prime}$-axis to the normal direction of circular cross-section of inclusion, where $x_{i}^{\prime}(i=1,2,3)$ denotes the coordinate taken to each inclusion.

When inclusions are oriented in order that their circular cross-sections are parallel to the $x_{1}$-axis and their normal directions distribute symmetrically around the axis, the increments of the effective elastic constants may be written by

$$
d C_{i j}^{k}=-\frac{1}{2} v_{k+1} G_{i j}^{k},
$$

where $G_{i j}^{k}$ 's are

$$
\begin{aligned}
& G_{11}^{k}=2 P_{11} \\
& G_{12}^{k}=\left(P_{12}+P_{21}+P_{13}+P_{31}\right) / 2 \\
& G_{13}^{k}=\left(P_{12}+P_{13}+P_{21}+P_{31}\right) / 2 \\
& G_{22}^{k}=2\left\{3\left(P_{11}+P_{33}\right)+P_{44}+P_{13}+P_{31}\right\} / 8 \\
& G_{23}^{k}=2\left\{P_{22}+3\left(P_{23}+P_{32}\right)+P_{33}-P_{44}\right\} / 8 \\
& G_{33}^{k}=2 P_{22} \\
& G_{44}=\left(P_{11}+P_{33}+P_{44}-P_{23}-P_{32}\right) / 2 \\
& G_{55}=G_{66}=\left(P_{55}+P_{66}\right) / 2 .
\end{aligned}
$$

In the case of isotropic orientation, the changes are written as follows;

$$
\begin{aligned}
A \equiv\left[2\left(P_{13}+P_{31}\right)+3 P_{33}+2 P_{44}\right] / 15 \\
B \equiv\left[8\left(P_{13}+P_{31}\right)+2 P_{33}-2 P_{44}\right] / 15 \\
C \equiv 2\left(2 P_{33}+3 P_{44}\right) / 15 \\
d C_{11}^{k}=8 P_{11} / 15+A \\
d C_{12}^{k}=\left[\left\{2 P_{11}+5\left(P_{12}+P_{21}\right)\right\} / 15+B\right] / 2 \\
d C_{13}^{k}=d C_{12}^{k} \\
d C_{22}^{k}=0.45 P_{11}+\left[\left(P_{12}+P_{21}\right)+P_{66}\right] / 24+A \\
d C_{23}^{k}=\left\{0.3 P_{11}+0.25\left(P_{12}+P_{21}\right)\right. \\
\left.\quad-P_{66} / 12+B\right\} / 2 \\
d C_{44}^{k}=\left[\left\{9 P_{11}-4\left(P_{13}+P_{31}\right)\right\} / 15\right. \\
\left.\quad+\left\{P_{66}-\left(P_{12}+P_{21}\right)\right\} / 6+C\right] / 2 \\
d C_{55}^{k}=\left[\left\{4\left(P_{11}-P_{13}-P_{31}\right)+5 P_{66}\right\} / 15+C\right] / 2 \\
d C_{66}^{k}=d C_{55}^{k} .
\end{aligned}
$$

Further, we define

$$
\begin{aligned}
\alpha \equiv & \left(d C_{i 1}^{k}+d C_{i 2}^{k}+d C_{i 3}^{k}\right) /\left(C_{i 1}^{M}+C_{i 2}^{M}+C_{i 3}^{M}\right) \\
& \quad \text { for } i=1,2, \text { or } 3 \\
\beta \equiv & d C_{j j}^{k} / C_{j j}^{M} \quad \text { for } j=4,5, \text { or } 6,
\end{aligned}
$$

the incompressibility $K$ and the rigidity $\mu$ of composite having inclusions of the volume fraction $v$ can be obtained from the following expressions,

$$
\begin{aligned}
& \kappa=\kappa^{M} \exp (-\alpha v) \\
& \mu=\mu^{M} \exp (-\beta v) .
\end{aligned}
$$

Here, $K^{M}$ and $\mu^{M}$ are the incompressibility and the rigidity of matrix.

\section{References}

Awata, Y., K. Mizuno, Y. Sugiyama, R. Imura, K. Shimokawa, K. Okumura, and E. Tsukuda, Surface fault ruptures on the northwest coast of Awaji Island associated with the Hyogo-ken Nanbu Earthquake of 1995, Japan, Zisin 2, 49, 113-124, 1996 (in Japanese with English abstract).

Barton, C. A., M. D. Zoback, and D. Moos, Fluid flow along potentially active fault in crystalline rock, Geology, 23, 683-686, 1995.

Brune, J. N., T. L. Henyey, and R. F. Roy, Heat flow, stress and rate of slip along the San Andreas fault, California, J. Geophys. Res., 74, 3821-3827, 1969.

Byerlee, J., Friction of rocks, Pure and Appl. Geophys., 116, 615-626, 1978. Chester, F. M., J. P. Evans, and R. L. Biegel, Internal structure and weakening mechanisms of the San Andreas fault, J. Geophys. Res., 98, 771-786, 1993.

Coyle, B. J. and M. D. Zoback, In situ permeability and fluid pressure measurements at $\sim 2 \mathrm{~km}$ depth in the Cajon Pass research well, Geophys. Res. Lett., 15, 1029-1032, 1988. 
Eshelby, J. D., The determination of the elastic field of an ellipsoidal inclusions, and related problems, Proc. Roy. Soc. Ser. A, 241, 376-396, 1957.

Feng, R. and T. V. McEvilly, Interpretation of seismic reflection profiling data for the structure of the San Andreas fault zone, Bull. Seism. Soc. Am., 73, 1701-1720, 1983.

Freudenthal, A. M., Statistical approach to brittle fracture, in Fracture, An Advanced Treatise, II, edited by H. Liebowitz, pp. 591-619, Academic Press, New York San Francisco London, 1968.

Geographical Survey Institute, The horizontal strain in Japan, II. 1994 1883, Technological data of Geographical Survey Institute, F-1_No. 10 Geographical Survey Institute, Tsukuba, 1997.

Handin, J., R. V. Hhager, Jr., M. Friedman, and J. N, Feather, Experimental deformation of sedimentary rocks under confining pressure: Pore pressure tests, Bull. Am. Soc. Petrol. Geol., 47, 717-755, 1963.

Hill, R., New derivation of some elastic extremum principles, in Progress in Applied Mechanics, The Prager Anniversary Volume, pp. 99-106, MacMillan, New York, 1963

Huenges, E., J. Erzinger, J. Kück, B. Engeser, and W. Kessels, The permeable crust: Geohydraulic properties down to $9101 \mathrm{~m}$ depth, J. Geophys. Res., 102, 18,255-18,265, 1997.

Iio, Y., Frictional coefficient on faults in a seismogenic region inferred from earthquake mechanism solutions, J. Geophys. Res., 102, 5403-5412, 1997.

Ikeda, R., Y. Iio, and K. Omura, In-situ stress measurements in NIED boreholes in and around the fault zone near the 1995 Hyogoken-Nanbu earthquake, Japan, The Island Arc, 10, 252-260, 2001

Ito, H., Y. Kuwahara, T. Miyazaki, O. Nishizawa, T. Kiguchi, K. Fujimoto, T. Ohtani, H. Tanaka, T. Higuchi, S. Agar, A. Brie, and H. Yamamoto, Structure and physical properties of the Nojima fault, by the active fault drilling, Butsuri-Tansa, 49, 522-535, 1996 (in Japanese).

Ito, H., Y. Kuwahara, and O. Nishizawa, Stress measurements by the hydraulic fracturing in the 1995 Hyogoken-nanbu earthquake source region, in Rock Stress, edited by K. Sugawara and Y. Obara, pp. 351-354, A. A Balkema., Rotterdam, 1997.

Jones, L. M., Focal mechanisms and the state of stress on the San Andreas Fault in southern California, J. Geophys. Res., 93, 8869-8891, 1988.

Kuwahara, Y. and H. Ito, Deep structure of the Nojima fault by trapped wave analysis, Proc. Int. W/S on the Nojima fault core and borehole data analysis, Nov. 22-23, Tsukuba, Japan, (GSJ Interim Rep. No. EQ/00/1 USGS Open-file Rep. 00-129), 283-289, 1999.

Li, Y.-G., J. E. Vidale, K. Aki, F. Xu, and T. Burdette, Evidence of shallow fault zone strengthening after the 1992 M7.4 Landers, California, Earthquake, Science, 279, 217-219, 1998.

Li, Y.-G., K. Aki, J. E. Vidale, and M. G. Alvarez, A delineation of the Nojima fault rupture in the M7.2 Kobe, Japan, earthquake of 1995 using fault zone trapped waves, J. Geophys. Res., 103, 7247-7263, 1998.

Li, Y.-G., J. E. Vidale, K. Aki, and F. Xu, Depth-dependent structure of the Landers fault zone from trapped waves generated by aftershocks, $J$ Geophys. Res., 105, 6237-6254, 2000.

Matsushima, S., Variation of the elastic wave velocities of rocks in the process of deformation and fracture under high pressure, Disas. Prevention Res. Inst. Kyoto Univ., Bull., 32, 2-8, 1960.

McGarr, A., M. D. Zoback, and T. C. Hanks, Implications of an elastic analysis of in situ stress measurements near the San Andreas Fault, $J$ Geophys. Res., 87, 7797-7806, 1982.

Nishigami, K., Investigation of deep structure of active faults using scattered waves and trapped waves, Seismogenic Process Monitoring, edited by H. Ogasawara, T. Yanagidani, and M. Ando, pp. 245-256, Balkema Rotterdam, 2000.

Norris, A. N., A differential scheme for the effective moduli of composites,
Mechanics of Materials, 4, 1-16, 1985.

Oppenheimer, D. H., P. Reasenberg, and R. W. Simpson, Fault plane solutions for the 1984 Morgan Hill, California, earthquake sequence: Evidence for the state of stress on the Calaveras Fault, J. Geophys. Res., 93 9007-9027, 1988

Paterson, M. S., Experimental Rock Deformation-Brittle Field, 254 pp., Springer-Verlag, Berlin Heidelberg New York, 1978.

Sato, N., Estimation of stresses in the vicinity of the Nojima fault, Awaji Is., Hyogo Pref. Japan, from core samples, Master thesis, Tohoku Univ., 87 pp., 1999 (in Japanese).

Sato, N., Y. Yabe, K. Yamamoto, and T. Hirasawa, Stresses at sites close to the Nojima earthquake fault estimated from core samples: III, Prog Abst. Seism. Soc. Japan, 1999 Fall Meeting, C14, 1999 (in Japanese).

Sibson, R. H., F. Robert, and K. H. Poulsen, High-angle reverse faults, fluid-pressure cycling, and mesothermal gold-quartz deposits, Geology, 16, 551-555, 1988 .

Tanaka, H., N. Tomida, N. Sekiya, Y. Tsukiyama, K. Fujimoto, T. Ohtani, and $\mathrm{H}$. Ito, Distribution, deformation and alteration of fault rocks along the GSJ core penetrating the Nojima fault, Awaji Island, Southwest Japan, in Proc. Int. W/S on the Nojima fault core and borehole data analysis, edited by H. Ito, K. Fujimoto, H. Tanaka, and D. Lockner, GSJ Interrim Rep., No. EQ/00/1, USGS Open-file Report 00-129, 81-101, 1999.

Tsukahara, H., R. Ikeda, and K. Yamamoto, In situ stress measurements in a borehole close to the Nojima Fault, The Island Arc, 10, 261-265, 2001

Watt, J. P., G. F. Davices, and R. J. O'Connell, The elastic properties of composite materials, Rev. Geophys. Space Phys. Res., 14, 541-563, 1976.

Yamamoto, K., Theoretical determination of effective elastic constants of composite and its application to seismology, Doctoral thesis, Tohoku Univ., 199 pp., 1980

Yamamoto, K., Strength distribution of microfracture elements in granites under compression test, in Proc. 3rd SEGJ/SEG Symp., pp. 327-334, Soc Exploration Geophys. Jpn., Tokyo, 1995.

Yamamoto, K., Estimation of fracture stress for intact rocks and possibility of long-term earthquake prediction, Zisin 2, 50, Sup. 169-180, 1998 (in Japanese with English abstract).

Yamamoto, K. and Y. Yabe, Stresses at sites close to the Nojima Fault measured from core samples, The Island Arc, 10, 266-281, 2001.

Yamamoto, K., M. Kosuga, and T. Hirasawa, A theoretical method for determination of effective elastic constants of isotropic composites, $\mathrm{Sci}$. Rep. Tohoku Univ., Ser. 5, Geophysics, 28, 47-67, 1981

Yamamoto, K., Y. Kuwahara, N. Kato, and T. Hirasawa, Deformation rate analysis: A new method for in situ stress estimation from inelastic deformation of rock samples under uni-axial compressions, Tohoku Geophys Journ. (Sci. Rep. Tohoku Univ., Ser. 5), 33, 127-147, 1990.

Yamamoto, K., N. Sato, and Y. Yabe, Strength of fault as inferred from the stresses measured in the vicinity of the Nojima fault (Extended abstract), Tohoku Geophys. Journ. (Sci. Rep. Tohoku Univ., Ser. 5), 36, 272-290, 2001.

Zoback, M. D. and J. H. Healy, In situ stress measurements to $3.5 \mathrm{~km}$ depth in the Cajon Pass Scientific Research Borehole: Implications for the mechanics of crustal faulting, J. Geophys. Res., 97, 5039-5057, 1992.

Zoback, M. D. and J. Townend, Implication of hydrostatic pore pressures and high crustal strength for the deformation of intraplate lithosphere, Tectonophys., 336, 19-30, 2001.

Zoback, M. D. et al., New evidence on the state of stress of the San Andreas fault system, Science, 238, 1105-1111, 1987.

K. Yamamoto (e-mail: yama@aob.geophys.tohoku.ac.jp), N. Sato, and Y Yabe 